\title{
OADOLESCENTECOMTRANSTORNODECONDUTA:UMESTUDOFILOSÓFICONO ÂMBITODAPSICOLOGIAEDUCACIONALEESPORTIVA
}

\author{
Janaina de Souza Marinho Teles Codea ${ }^{1}$ \\ Heron Beresford
}

\section{Resumo}

\begin{abstract}
O valor de uma intervenção da psicologia escolar/educacional e esportiva no adolescente com transtorno de conduta social, sob o ponto de vista moral e existencial, surgiu da necessidade de uma proposta educacional de cunho psicológico, para tal indivíduo. O presente estudo visou estabelecer uma fundamentação filosófica de natureza fenomenológica e axiológica existencial transubjetiva como referência para uma intervenção positiva da psicologia escolar/educacional e esportiva, por meio de atividades físicas, com o indivíduo em questão. Buscou também compreensões fenomenológica e axiológica do adolescente com o transtorno citado e uma ordenação axiológica relacionando tais compreensões à atividade física. A metodologia utilizada foi o método fenomenológico com suas três etapas, substituindo-se a terceira pela ordenação axiológica. Os resultados permitiram verificar que a fundamentação filosófica evidenciada adequou-se como referência para uma intervenção positiva da psicologia escolar/educacional e esportiva na vida do adolescente com transtorno de conduta social.

Palavras-chave: Psicologia esportiva; Adolescência; Transtorno social de conduta.
\end{abstract}

\section{The Adolescent Being with Social Behavior Problem: A Phylosofical Study at Educational and Sporting Psychology Extent}

\begin{abstract}
The value of a psychological intervention related to scholar/educational and sport matters, focusing the social misbehavior adolescent on the moral and existential point of view. The study aimed a philosophical route in a phenomenological and axiological existential methodology. This was as a reference to a positive intervention of the scholar/educational and sportive psychology, through physical activities with the adolescent The methodology used was : phenomenological method with its' three stages, substituting the third by the axiological ordination. The philosophical fundamentation had shown fit as a reference to a positive intervention of the scholar/educational and sportive psychology with the adolescent

Keywords: Sporting psychology; Adolescent; Social behavior problem.
\end{abstract}

\section{NTRODUÇÃo}

transtorno de conduta social na adolescência, sob o ponto de vista moral, é, em alguns casos, uma expressão existencial do adolescente que está envolvido em um contexto de circunstância, facticidade e corporeidade com carências essenciais de diferentes naturezas (Ortega \& Gasset, 1947; Mondin, 1980; Frondizi, 1991; Beresford, 1994, 1999; Heidegger, 1999a e b; Merleau-Ponty, 1999; Heidegger 2001; 2002; Reale, 2002). Essas podem ser compreendidas por meio dos pressupostos teóricos da filosofia fenomenológica e axiológica existencial transubjetiva.
Para isso, pode-se considerar o trabalho de Kohlberg (1992), Vieira (1993), Piaget (1994), Puig (1999) e Machado (2001). Em tal perspectiva, o adolescente é percebido conforme os seguintes conceitos: circunstância, razão, vida e dilema (Ortega \& Gasset, 1947); temporalidade, facticidade, angústia, escolha de um caminho autêntico ou inautêntico, tomada de decisão e transcendência (Heidegger, 1999); corpo e corporeidade (Merleau-Ponty, 1999). Esses possibilitam a compreensão acerca do como o adolescente valoriza sua existência organizando sua realidade, e,

\footnotetext{
${ }^{1}$ Universidade Castelo Branco / Universidade Estácio De Sá.

${ }^{2}$ Universidade Castelo Branco.
} 
conseqüentemente, como este está se construindo como identidade humana.

Tem a facticidade de estar imerso em um contexto sociohistórico que se organiza. Por exemplo, a partir de princípios morais e éticos com os quais ele precisa interagir, e isto passa a ser sua circunstância, já que ela não se refere somente ao que percebe do mundo, mas também ao que lhe é imposto.

Sua temporalidade é única e intransferível, pois pela corporeidade vivencia situações em um tempo próprio atribuindo a essas significados pessoais. O que concorre para o surgimento de conflitos ou dilemas entre ele e os pares, em virtude da diferença de carências e, conseqüentemente, de tomada de decisões frente às diversas escolhas. Porém, tal dinâmica se efetiva como existencial no momento em que o adolescente se sente angustiado por se perceber em conflito e com a emergência de se posicionar como um ser cultural e moral em um contexto sociohistórico.

Há de se considerar que o adolescente que apresenta condutas e comportamentos motores característicos do transtorno de conduta social, sob o ponto de vista moral, não se angustia com o que faz e com o julgamento alheio, por se encontrar em uma temporalidade permeada por uma condição moral diferente da vivenciada pelos outros que estão em relação com ele. Logo, ele vivencia uma moralidade individual que se apresenta socialmente por uma escala de valores morais e éticos.

Conforme Piaget (1994) esse adolescente está vivenciando uma moralidade identificada como autônoma que segue a heterônoma própria da infância. Na primeira, existe uma concepção de regras condizente com o consenso geral, isto é, não basta dizer o que deve ser feito, e sim, fazer junto para que a regra não se apresente como apenas uma imposição, mas algo compartilhado e, portanto, aceito de maneira recíproca. Nessa etapa de vida, geralmente, surgem os conflitos ou dilemas entre a hierarquia de valores morais do adolescente com a de seus familiares/responsáveis e professores por causa do comportamento impositivo destes em relação ao primeiro no que concerne ao que é certo ou justo. Assim, é imposto ao adolescente uma escala de valores morais que não corresponde às suas necessidades o que gera neste uma insatisfação que emerge socialmente sob forma de agressão ao que está a sua volta, por exemplo.

O comportamento impositivo de tais figuras afetivas e de autoridade decorre do fato de estas perceberem o adolescente a partir da fase heterônoma. Nessa, ele acatava as regras impostas, a priori, sem uma conduta crítica valorativa, isto é, mesmo insatisfeito era capaz de seguir o proposto devido ao vínculo afetivo com as figuras de autoridade, bem como pelo receio de punição, pois reconhecia tais figuras como tendo mais poder de decisão que ele. No entanto, na fase de autonomia sente a necessidade de pensar e refletir sobre as regras de conduta e comportamentos sociais próprias e também alheias, pois já está em processo de desenvolvimento da moralidade autônoma e consensual. Isto incomoda aqueles que não estão habituados a ser questionados e que, geralmente, utilizam-se do argumento da força e não da força do argumento para se fazerem compreender pelo adolescente. Logo, essas pessoas não conseguem perceber que o adolescente está em busca de uma identidade pessoal, bem como de um sentido para o seu existir, o que implica na construção de uma escala de valores morais própria.

$\mathrm{O}$ adolescente com transtorno de conduta escolheu uma forma de existir compatível com uma identidade negativa, o que caracteriza uma possível falta de autenticidade de sua existência. Continua carente tentando fugir de sua facticidade, ou seja, ser ao mesmo tempo livre e responsável por sua vida utilizando-se de sua corporeidade. Para Köhlberg (1992), tal adolescente está no nível pré-convencional do desenvolvimento moral humano, embora pela faixa etária devesse estar saindo do nível convencional para o pós-convencional. Ele não consegue se articular com o social compreendendo as regras e percebendo que do mesmo ele faz parte, construindo e definindo seus valores morais a partir de suas carências, identificando-se com um projeto para tornar-se adulto.

O nível pré-convencional implica em uma postura heterônoma. $\mathrm{O}$ adolescente tem seu comportamento sob uma perspectiva egocêntrica, não considerando as diferenças interpessoais e os interesses alheios. Reage fisicamente às considerações verbais e não tem discernimento sobre a influência da autoridade alheia em sua vida por causa da noção equivocada de limite individual e social. Isto porque desenvolve um individualismo que o dificulta perceber que todos os outros também têm seus interesses, o que gera conflito, pois o correto se torna relativo.

Pelo exposto, verificou-se que o adolescente necessita ser estimulado para desenvolver-se moralmente atingindo o nível pós-convencional de moralidade e vivenciando sua autonomia moral por meio 
da moral consensual. Isto só será efetivado a partir de uma educação moral que lhe possibilite vivenciar, como corporeidade, o imperativo categórico de Kant (2002), dentre outros aspectos existenciais. A educação moral do adolescente possibilitaria uma reflexão acerca de sua percepção do outro, aprendendo a tratar o homem como um fim, agregando ou instaurando o valor de pessoa ao ser do homem, e não tratando-o como um simples meio, ou coisificando-o ao retirar o valor humano ou de pessoa humana de tal ser.

Assim, esse adolescente poderá ser capaz de desenvolver-se com uma identidade positiva sob o ponto de vista moral encontrando seu caminho autêntico, isto é, suprindo o que lhe é necessário, mas que não especificamente lhe proporciona prazer ou simplesmente satisfaz seus sentimentos e vontades próprias à revelia. Ele estará articulando a liberdade com a responsabilidade face às circunstâncias permeadas por dilemas, construindo uma vida nas bases da razão prática que possibilita a ocupação no tempo e no espaço de maneira consciente e operante, o que gera angústia, mas que favorece o aprendizado a partir da mudança de pontos de vista.

Mas, como fazer isto, se a partir dos pensamentos de Kaplan e Sadock (1990), Kohlberg (1992), Piaget (1994) e Ballone (2002) acerca das características e dos sintomas comportamentais do adolescente com transtorno de conduta social, não se angustia, não se incomoda com o que faz e nem com o prejuízo causado aos outros, pois ele se encontra com uma postura caracterizada pelo egoísmo, pela moral individual e pelo juízo pré-convencional?

A possibilidade de angustiar-se está em sentir-se incomodado e para tal ele necessita vivenciar fisicamente questões que, a priori, só estão no âmbito cognitivo, a fim de que elas possam ser identificadas na dimensão psicoemocional. A valoração de algo só se consubstancia pela vivência, conforme Scheler (citado por Beresford, 1999). Isso implica em sensação (registro biofísico e biopsicoemocional) e percepção (atribuição de significado como expressão sociohistórico, cultural e moral).

A intervenção da psicologia escolar/educacional e esportiva no adolescente com transtorno de conduta social, sob o ponto de vista moral, precisa estar atrelada à atividade física como um instrumento de vivência da angústia, considerada como uma condição para a reeducação moral e revisão de valores morais e éticos.
Logo, o esporte, os exercícios físicos e as danças não são práticas que devam ser ministradas por psicólogos e sim pelo profissional da educação física. No entanto, as demais atividades físicas, como as utilitárias e de lazer são vivenciadas por todos os seres humanos em diferentes níveis de expressão motora.

Para que a atividade física, conforme o conceito da Federation Internationale d' Education Physique - FIEP (2000), possa se tornar um instrumento eficiente de prevenção, diagnóstico e acompanhamento psicológico do adolescente em questão nesta pesquisa, ela foi alicerçada na filosofia fenomenológica e axiológica existencial transubjetiva. Tal teoria possibilita conhecer a vida do adolescente a partir de conceitos, como: circunstância; dilema; temporalidade; facticidade; angústia; tomada de decisão; caminho autêntico e inautêntico; transcendência; corporeidade; carências de diferentes naturezas; consciência reflexiva e conduta moral no contexto sociohistórico entre outros já citados. A relevância de tal referencial teórico associa-se ao fato de que o adolescente em questão apresenta dificuldade em organizar suas idéias a partir do vivido, pois este não preencheu positivamente suas carências humanas, não valorizando eticamente o vivenciado e, sim, insistindo na busca por um caminho que não é autêntico.

O comportamento motor desse adolescente caracteriza-se pela presença ou ausência da intencionalidade operante, o que mostra seu desenvolvimento moral por intermédio de sua corporeidade. Isso evidencia que seu estar no mundo pode tornar-se autêntico a partir das escolhas que faz face às circunstâncias vivenciadas. Pode, por meio da atividade física, experienciar pela razão prática a angústia de ter de escolher e decidir o que melhor preenche suas carências, isto é, o que é necessário para si, pois estará vivenciando dilemas e conflitos que exigem condutas e comportamentos sociais compatíveis com a moral consensual.

Tal vivência possibilita ao adolescente movimentarse em direção ao que necessita e não simplesmente ao que lhe dá prazer. Caso não haja a intervenção da psicologia escolar/educacional e esportiva por meio de tal recurso, o ente adolescente com transtorno de conduta social continuará sem se perceber como um projeto de ser humano, pois se projeta como um organismo biofísico e biopsicoemocional sem compromisso com sua condição de um ser sociohistórico, moral e ético. Seu desenvolvimento moral apresenta falhas que contribuem 
para um desvio ou distanciamento do que sociohistoricamente se considera como um ser humano.

Isso ocorre por causa de sua condição de estar lançado no mundo e necessitado de referenciais que o auxiliem a se construir como ser humano atribuindo ao seu estar-no-mundo um valor moral condizente com a moral consensual. Portanto, por meio do tipo de atividade física, proposto nessa pesquisa, se efetiva a possibilidade de vivenciar questões morais e éticas conforme a intencionalidade daqueles que a ministrem, em geral os profissionais de educação e, em específico, o psicólogo escolar/educacional e esportivo. Bem como, dos que a praticam, isto é, os alunos, em geral, e estes com transtorno de conduta social sob o ponto de vista moral, em específico.

Operacionalmente, o adolescente ao executar uma atividade física sente e começa a perceber, valorizando o que vivencia. A dialética entre corporeidade e atividade física no âmbito da moralidade favorece que o ser-nomundo seja capaz de modificar-se em virtude da tomada de consciência reflexiva sobre sua forma autêntica e não autêntica de estar-no-mundo. Ele pode verificar, em sua experiência, o que está ou não tendo valor quanto ao que lhe é necessário. Essa reflexão surge mediante dilemas ou conflitos. E também, na vivência da angústia que permeia a tomada de decisão frente à urgência de escolhas em circunstâncias tempo-espaciais, considerando princípios morais e éticos que norteiam o correto e o justo.

Essa dinâmica se evidencia como existencial, pois vivencia a decisão e a escolha em face de um dilema, pois ele tem um limite temporal para posicionar-se frente às suas circunstâncias. Assim, precisa aprender a utilizar-se de sua intencionalidade operante a fim de sentir, perceber e executar condutas e comportamentos motores que preencham positivamente suas carências, o que só se torna possível pela corporeidade que viabiliza o serno-mundo e o seu movimentar construindo sua realidade e dando forma à sua existência.

Portanto, a atividade física é o instrumento ou o estímulo que favorece a expansão da corporeidade. Nesse sentido, o presente estudo visou estabelecer uma fundamentação filosófica de natureza fenomenológica e axiológica existencial transubjetiva como referência para uma intervenção positiva da psicologia escolar/ educacional e esportiva, por meio de atividades físicas, com o indivíduo em questão. Buscou também compreensões fenomenológica e axiológica do adolescente com o transtorno citado e uma ordenação axiológica relacionando tais compreensões à atividade física.

\section{MÉTOD0}

A estratégia metodológica utilizada foi o método fenomenológico, proposto por Husserl (1990), denominado intuição fenomenológica eidética, substituindo-se sua terceira etapa, a da reflexão fenomenológica, pela reflexão ontognoseológica, proposta por Reale (2002). Teve como estratégia de operacionalização uma reflexão críticohistórica e dialética ou uma ordenação axiológica. Para complementar tal ordenação axiológica se utilizou o referencial de Frondizi (1991) sobre o valor como qualidade estrutural que preenche positivamente uma carência.

A operacionalização da primeira fase do método descrição do objeto - consistiu na descrição do adolescente com transtorno de conduta social, sob o ponto de vista moral. Clarificando suas necessidades provindas do estado de privação ou carência ou vacuidade: bio-física, bio-psicoemocional, bio-moral ou humana, bio-sócio-histórica.

A segunda fase do método - redução das essências - implicou em chegar na essência axiológica do conteúdo descrito na etapa anterior contribuindo para uma reflexão histórico-axiológica e dialética, isto é, uma ordenação axiológica que fundamentou uma interpretação do ente adolescente em questão com um transtorno decorrente do conflito entre a hierarquia de valores morais deste com a de seus responsáveis, familiares e professores.

A terceira fase do método fenomenológico foi substituída pela reflexão ontognoseológica, fundamentada pelo método crítico-histórico e crítico-axiológico proposto por Reale (1988), no intuito de alcançar a consecução do terceiro objetivo específico, ou seja, elaborar uma ordenação axiológica do objeto prático deste estudo. Essa é a conduta motora representada pela intervenção do profissional de psicologia escolar/educacional e esportiva a partir das respectivas compreensões fenomenológica e axiológica desenvolvidas nas fases anteriores acerca do adolescente com transtorno de conduta social, sob o ponto de vista moral, como objeto formal deste estudo.

A hipótese racional dessa pesquisa, com a seguinte formulação: supõe-se que uma fundamentação filosófica de natureza fenomenológica e axiológica existencial 
transubjetiva fosse capaz de servir de referência para uma intervenção positiva do profissional de psicologia escolar/educacional e esportiva, por meio de atividades físicas, com o adolescente com transtorno de conduta social, sob o ponto de vista moral, decorrente do conflito entre a hierarquia de valores morais deste com a de seus responsáveis, familiares e professores, possuiu os seguintes critérios de comprovação: Pelo absurdo, ou seja, evitou-se o absurdo por meio da coerência lógica estabelecida neste estudo: problema, objetivo geral, objetivos específicos, hipótese, fundamentação teórica e metodologia, para se assegurar, pelo menos em parte, a solução do problema que o originou; Pelas consequiências inferidas de um princípio já anteriormente demonstrado, isto é, princípios da "ausência de contradição" e de "causalidade" advindos das verdades lógica e ontológica; Pela concordância com outras teses já estabelecidas, comprovando a coerência racional e lógica com a problemática em questão a partir da fundamentação teórica; Pela capacidade de unificar, observada na consecução das fases do método fenomenológico que corresponderam à compreensão axiológica; compreensão fenomenológica e ordenação axiológica. Observados esses critérios de controle, comprovação, verificação ou demonstração a hipótese racional desta pesquisa ultrapassou a experiência sensível e permaneceu atrelada ou guiada por sua necessidade lógica.

\section{Resultados e Discussão}

Compreendeu-se a intervenção da psicologia escolar/ educacional e esportiva com o adolescente com transtorno de conduta social, sob o ponto de vista moral, por meio da atividade física, conforme a FIEP (2000), a partir da proposta dos novos Parâmetros Curriculares Nacionais (PCNs) elaborados pelo MEC-Ministério da Educação e do Desporto, apresentados à sociedade no fim de 1997. Na proposta dos PCNs se prevê a temática da moralidade, ou seja, conceito de moral, valor e ética como tema transversal em educação para ser trabalhado por todos os profissionais de educação, em geral, e os professores de todas as disciplinas, em específico.

Nessa pesquisa se propôs uma fundamentação teórico-filosófica da atividade física para o trabalho interdisciplinar entre o psicólogo escolar/educacional e esportivo e os demais profissionais de educação.
Principalmente os professores e, em especial, os de educação física por estarem habilitados a utilizarem-se também dos exercícios físicos, das danças e dos esportes para educar moralmente seus alunos.

Vieira (1993) mostrou a eficiência do trabalho da educação física na educação moral de alunos entre 15 e 17 anos. Identificou que os praticantes de esporte escolar apresentam um raciocínio moral equivalente, tanto em dilemas morais da vida diária quanto da vida esportiva. O psicólogo escolar/educacional e esportivo em uma equipe interdisciplinar no âmbito educacional servirá de um referencial instrucional para os demais profissionais, principalmente os professores acerca da utilização de atividades físicas fundamentadas na filosofia fenomenológica e axiológica existencial transubjetiva, no adolescente com transtorno de conduta social, sob o ponto de vista moral.

Os professores de outras disciplinas poderão executar atividades físicas que estimulem a vivência de situações pertinentes aos dilemas morais da vida diária por meio, por exemplo, de uma técnica conhecida como enfoque socioafetivo. Esse enfoque tem como um de seus objetivos estimular a vivência de sentimentos e emoções que servirão de base para uma reflexão moral (Puig, 1999).

Puig (1999) identificou que a prática do enfoque socioafetivo implica em criar um clima positivo na classe, apresentar e desenvolver a experiência simulada. Permitindo vivenciar certas situações reais, analisar e refletir a experiência, os sentimentos provocados e a realidade que pretendia mostrar e transferir as aquisições para outras realidades.

A operacionalização de tal técnica foi enfatizada pelo autor por meio do exemplo de uma professora de matemática com exercícios de geometria e teoria. Nesse caso, a professora pôde estimular a reflexão sobre princípios de igualdade social e justiça. No entanto, a mesma técnica fundamentada na filosofia fenomenológica e axiológica existencial transubjetiva, no adolescente objeto desta pesquisa, não estimulará apenas a simulação de uma situação real e sim a manifestação ou a emersão de uma experiência pessoal dos alunos. Isso propiciará a reflexão acerca de suas carências e de conteúdos, como: circunstância, vida, razão prática, dilema, temporalidade, facticidade, angústia, escolha, tomada de decisão, corporeidade e transcendência, a fim de que os presentes na vivência possam identificar seu movimento de ser-no-mundo, verificando se estão 
ou não se construindo como seres humanos e por quê. Assim, o professor poderá desempenhar seu papel de Dasein, ajudando os alunos a preencherem suas carências bio-sócio-históricas como as pertinentes aos referenciais socioafetivos e morais que auxiliam no processo de formação de uma identidade positiva sob o ponto de vista moral.

Tal procedimento deve ser utilizado objetivando, em um primeiro momento, a vivência da angústia (já que o adolescente em questão apresenta dificuldade em sentila) e, em seguida, estimular a tomada de decisão frente às possibilidades de escolhas que irão surgir mediante a consciência reflexiva sobre o significado da existência. Essa dinâmica existencial propiciará a identificação das fases (heterônoma e autônoma) e dos níveis (préconvencional, convencional e pós-convencional) de moralidade em que os alunos se encontram, o que favorece a aquisição de subsídios para que o professor consiga estimular os alunos de maneira eficiente, concorrendo para o desenvolvimento moral dos mesmos já que estará incentivando-os no processo de atribuição de valores morais e éticos às situações experienciadas. Esse procedimento profissional promoverá condições para que o adolescente consiga desenvolver-se de modo a conquistar sua autonomia moral, em uma perspectiva da moral consensual, o que favorecerá a ele o convívio social positivo, segundo os princípios morais e éticos condizentes com tal moral.

A técnica enfoque socioafetivo pode ser utilizada com o adolescente objetivando suprir as carências biomorais ou humanas, e algumas carências biopsicoemocionais como, por exemplo: adotar modelos como referenciais de moralidade e ética no processo de construção de valores; aprender a expressar-se socialmente considerando seus limites e os alheios; assumir responsabilidades face ao dilema: direitos e deveres; aprender a colocar em palavras o que naturalmente expressa por gestos; gerenciar ou administrar a sua perspectiva de regras com a vivenciada pela sociedade.

Da mesma forma, também se consegue trabalhar as consequiências do déficit de serotonina e do elevado nível de testosterona, identificados como componentes bioquímicos que constituem as carências biofísicas, geralmente presentes no adolescente com transtorno de conduta social. Tais conseqüências se referem à alta tolerância à punição, ou seja, dificuldade em compreender o significado de justiça, já que a perda e a restrição ou cerceamento é considerado um afronto, e ao comportamento agressor que implica no desrespeito aos limites individuais alheios.

A operacionalização da referida técnica implica em amenizar sintomas, como: prejuízo no funcionamento social e escolar (comportamento anti-social), desobediência, comportamento desafiador e de oposição a figuras de autoridade, comportamento de crueldade $\mathrm{e}$ hostilidade com relação ao grupo de pares, crianças e jovens da mesma faixa etária, vandalismo, mentiras persistentes, excessiva agressividade.

Para se compreender melhor a utilização da atividade física no adolescente em questão, destaca-se a relação entre algumas finalidades da educação moral e um tipo de atividade chamada Role-playing: Aquisição de critérios de juízo moral - A prática da atividade de roleplaying torna-se imprescindível na aquisição de critérios de juízo moral. Compreende os seguintes passos: criar um clima de confiança e de participação no grupo; explicar com clareza as normas e os passos que serão seguidos na dinâmica; realizar a dinâmica; analisar e valorizar ou valorar os conteúdos surgidos durante a dinâmica. Isso concorre para a mudança de pontos de vista e para a transcendência.

Essa técnica pode ser apresentada aos alunos, segundo o propósito do psicólogo e/ou professor, de três formas, a saber: Role-playing na lousa; Role-playing tipo conferência de imprensa; e Role-playing tipo resolução de conflitos. Essa última é de extrema importância no trabalho com o adolescente objeto de estudo desta pesquisa. Ela estimulará a linguagem verbal a fim de se evitar uma expressão comportamental inconseqüente, por exemplo: O professor solicita que os alunos escrevam em um papel uma situação conflitante vivenciada recentemente. Elege, por sorteio aleatório ou votação, uma delas. Divide a turma em quatro subgrupos: dois para defender com argumentos uma das pessoas envolvidas no conflito, e os outros dois para representar a segunda pessoa. Em seguida se inicia o debate com o objetivo de se encontrar uma solução consensual para o conflito.

Tal técnica favorece a estimulação e o preenchimento de carências biopsicoemocionais e biossociais do adolescente em voga equivalentes à dificuldade de expressão pela linguagem verbal e a manifestação do comportamento social considerando o coletivo. Dessa forma, se ameniza e/ou se extirpa sintomas, como: baixa auto-estima, manipulação alheia em benefício próprio (egocentrismo), comportamentos de destrutividade, 
furtos e violência física (agressão), ofensas verbais, postura desafiadora, agitação, impulsividade e déficit de habilidade de comunicação, dispersão, desobediência às regras.

Essas atividades estão relacionadas, segundo FIEP (2000), como utilitárias e experiências de lazer. Porém, se verifica o exercício físico, como jogo, e o esporte como subgrupos das atividades físicas pelas quais também se realizará a intervenção da psicologia escolar/ educacional e esportiva com o adolescente em questão, desde que ela esteja inserida em uma proposta interdisciplinar com a educação física.

Exemplificando, na rede municipal de ensino do Rio de Janeiro já existe a prática da atividade física como exercício físico, vivenciado por meio do jogo. E o esporte com o objetivo de estimular os alunos a criarem novas regras para os jogos já conhecidos, inaugurando novos jogos, por exemplo o "bandeirobol", que é uma articulação entre o pique-bandeira e o handebol.

Em que consiste tal jogo? O jogo começa como um handebol gigante, em que cada grupo, com a posse de bola deve lançá-la para o gol da equipe adversária, ao sinal de início. Daí, as regras da brincadeira misturamse com as do pique-bandeira e nenhum pode atravessar para o campo adversário, em momento algum. $\mathrm{O}$ primeiro objetivo de cada equipe é acertar a bola no gol ou no alvo que possa substituí-lo. Quando a meta é alcançada, o jogador que aguarda na área proibida adversária tenta pegar a bola e tem um minuto, cronometrado pelo professor, para atravessar para o próprio campo. Na ocasião, ele só poderá ser"colado" por dois jogadores previamente indicados para esta tarefa. Os demais continuarão tentando lançar a bola no gol do time oponente para liberar seu jogador em espera na área proibida. Regras importantes - Nenhum jogador pode interceptar a bola dentro da área proibida para evitar que ela atinja o alvo. Se isso acontecer, o jogador em espera ficará liberado imediatamente, sem a necessidade de fazer um gol liberado. Além dos dois defensores designados no início de cada ponto disputado, nenhum jogador pode atrapalhar a corrida daquele em espera. Se o fizer, será computado um ponto contra a sua equipe e o jogo será reiniciado. Quando uma equipe faz o gol liberado, não pode ficar retendo a bola lançada para o seu gol pelo time adversário. Essa deve ser devolvida para que o outro time permaneça com chances de liberar seu jogador em espera. Todos os papéis devem ser trocados a cada ponto, para que o maior número de crianças se revezem nas tarefas (Machado, 2001).

Com base na proposta dos PCNs, nessa atividade o professor de educação física, idealizador da proposta, também estimula os alunos a escreverem livretos sobre as alterações das regras que implicaram em jogos alterados e criados. Com isso, operacionaliza a transversalidade com a disciplina de português.

A psicologia escolar/educacional e esportiva adaptando essa atividade física à proposta teóricofilosófica dessa pesquisa trabalhará conteúdos, como circunstância, facticidade, temporalidade e corporeidade sob a luz da moral consensual com o adolescente com transtorno de conduta social, sob o ponto de vista moral. Interdisciplinarmente com os professores de educação física pelo exercício físico e pelo esporte, contribuirá para o preenchimento de algumas carências do ente em questão, como gerenciamento da agressividade por causa do alto nível de testosterona; tolerância à punição associada ao déficit de serotonina; reflexão sobre a relação e o dilema liberdade-responsabilidade (perdas/ ganhos; direitos/deveres); expressar-se socialmente considerando seus limites e os alheios; administrar sua perspectiva de regras com a vivenciada pela sociedade; adotar modelos como referenciais de moralidade e ética, favorecendo a construção dos próprios valores; vivenciar o respeito e o dever como princípios éticos; agregar valor humano a ele e aos outros adolescentes.

Dessa forma, se previne, minimiza ou extirpa sintomas do transtorno de conduta social, como indisciplina escolar, dificuldade do aluno em se manter envolvido nas tarefas e completá-las no tempo previsto para a sua execução, agressividade como agressão, escassez de habilidades pró-sociais, desobediência às regras, exclusão do ambiente escolar e social, déficit de atenção aliado à hiperatividade, baixo rendimento, impulsividade acima da média e dificuldades para lidar com frustrações o que ocasiona comportamentos como xingar, chutar e responder sem refletir a colegas e professores.

Pelo exposto, constatou-se que existem procedimentos técnicos pertinentes à relação entre a atividade física e a educação moral capazes de serem utilizados pelos profissionais de educação, em geral, e pelo psicólogo escolar/educacional e esportivo, em específico. Pode ser utilizado com o adolescente com transtorno de conduta social, sob o ponto de vista moral, adotando-se como parâmetro ou referencial teórico a filosofia fenomenológica e axiológica existencial transubjetiva. 
No entanto, isso só ocorrerá se tais profissionais desempenharem a função correspondente ao papel do Dasein, ou seja, ser uma co-presença que auxilia o adolescente a se construir um "ser-para-si-mesmo próprio" e um ser-junto ou um ser-com, inaugurando a presença como um ser-no-mundo condizente com o projeto de ser humano. Sendo assim, demonstrou-se que, se pode enfrentar ou, ao menos, minimizar o transtorno de conduta social do adolescente decorrente do conflito entre a hierarquia de valores morais deste com a de

\section{REFERÊNCIAS}

Ballone, G. J. (2002). Adolescência e puberdade. PsiqWeb psiquiatria geral. Disponível em: <http://sites.uol.com.br/ gballone/infantil/adoelesc.html>. Acessado em 04/09/ 2002.

Beresford, H. (1999). Valor: saiba o que é. Rio de Janeiro: Shape.

Beresford, H. (1994). A ética e a moral social através do esporte. Rio de Janeiro: Sprint.

Fedèration Internationale D'Education Physique - FIEP. (2000). Manifesto mundial de educação física. Paraná: Federação Internacional de Educação Física.

Frondizi, R. (1991). Qué son los valores? Introducción a la axiología. México: Fondo de Cultura Econômica.

Heidegger, M. (1999a). Introdução à metafísica (4⿳a ed.). Rio de Janeiro: Tempo Brasileiro.

Heidegger, M. (1999b). Ser e tempo ( $8^{\mathrm{a}}$ ed. Parte I). Petrópolis: Vozes.

Heidegger, M. (2001). Ser e tempo ( $8^{\mathrm{a}}$ ed. Parte II). Petrópolis: Vozes.

Heidegger, M. (2002). Ser e tempo (11 ${ }^{\mathrm{a}}$ ed. Parte I). Petrópolis: Vozes.

Husserl, E. (1990). A Idéia da fenomenologia. Lisboa: Edições 70.

Kant, I. (2002). Fundamentação da metafísica dos costumes e outros escritos. São Paulo: Martin Claret.

Kaplan, H. I. \& Sadock, B. J. (1990). Compêndio de psiquiatria ( $2^{\mathrm{a}}$ ed.). Porto Alegre: Artes Médicas. seus responsáveis, familiares e professores no contexto escolar/educacional e esportivo.

Concluiu-se esta pesquisa demonstrando que, ela contribuiu, pelo menos em parte, para minimizar o problema que lhe deu origem, que é a necessidade de se estabelecer uma proposta educacional de cunho psicológico que atue com adolescentes que manifestam transtorno de conduta social, sob o ponto de vista moral, como conseqüência do conflito entre a hierarquia de valores morais destes com a de seus responsáveis, familiares e professores.

Kohlberg, L. (1992). Psicología del desarrollo moral. Bilbao (Espanha): Desclée de Brouwer.

Machado, K. (2001). Educação Física se faz com criatividade. Disponível em: <http://www.appai.org.br/Jornal_Educar/ jornal16/educação_fisica/criatividade.htm>. Acessado em: 01/04/2002.

Merleau-Ponty, M. (1999). Fenomenologia da percepção (2a . ed.). São Paulo: Martins Fontes.

Mondin, B. (1980). Introdução à Filosofia: problemas, sistemas, autores, obras. São Paulo: Paulinas.

Ortega Y Gasset, J. (1947). Obras completas. Madri: 6v.

Piaget, J. (1994). O Juízo Moral na Criança (2a . ed.). São Paulo: Summus.

Puig, J. M. (1999). Ética e valores: métodos para um ensino transversal (2. ed.). São Paulo: Casa do Psicólogo.

Reale, M. (1988). Introdução à Filosofia. São Paulo: Saraiva. Reale, M. (2002). Introdução à Filosofia (4ª . ed.). São Paulo: Saraiva.

Vieira, J. L. L. (1993). Avaliação do desenvolvimento moral de adolescentes em dilemas morais da vida diária e da prática esportiva. Dissertação de Mestrado. Universidade Federal de Santa Maria. Rio Grande do Sul.

Recebido em: 01/07/03

Revisado em: 21/08/04

Aprovado em: 18/02/04 